\title{
CHEST ASSESSMENT AND SIMPLE LUNG FUNCTION TESTS
}

\author{
C. P. RODśtTH, B.Sc. (Physiotherapy) (Witwatersrand), M.Sc. (Strathclyde), M.C.S.P., Dip.T.P.*
}

\section{SUMMARY}

The main elements of a chest assessment are outlined. Elementary measurements which should be taken by physiotherapists are described. Simple lung function tests which are within the capability of physiotherapists who are closely concerned with chest patients are explained in some detail. The tests concerned are: Peak Expiratory Flow Rate, Forced Vital Capacity, Forced Expiratory Volume in 1 sec. and the ratio Forced Expiratory Volume in 1 sec./Forced Vital Capacity as a percentage. Four of the more advanced tests and their underlying concepts which are more the domain of special pulmonary testing laboratories are briefly described.

A thorough assessment of the patient is an essential tequirement prior to deciding on treatment modalities and in order to monitor progress.

The classical chest assessment comprises:

Subjective examination - eliciting the symptoms by taking the history and asking the patient to describe the problem.

Objective examination - eliciting the signs in the time-honoured sequence of: observation, palpation, percussion, auscultation and special investigations.

Interpretation of the findings by correlating the results of the examinations and comparing them with normal values.

\section{OBJECTIVE EXAMINATION}

\section{Observation}

The shape of the chest together with the rate, rhythm and pattern of chest wall movement are observed.

\section{Palpation}

Placing the hands on the chest usually confirms the pattern of breathing previously observed and may reveal the presence of secretions by the vibrations produced when air moves over them. Palpation allows the observer to gain a general idea of the location of such secretions.

\section{Percussion}

Tapping the dorsum of the middle phalanx of the middle finger of the non-dominant hand placed flat on the chest wall with the tip of the middle finger of the dominant hand. The quality of the vibrations so produced is perceived both with the rest of the hand and by sound. This reveals either a normal resonance, increased resonance as with a collapsed lung or severe emphysema or decreased resonance (dullness) as with consolidation of the lung or pleural thickening.

\section{Auscultation}

Interpretation of the sounds heard with a stethoscope was fully dealt with in the previous issue (Mor-
rison, 1980).

\section{Special Investigations and Measurements}

Radiography. The interpretation of this extremely important special investigation is beyond our scope here.

\footnotetext{
* Senior Lecturer, Department of Physiotherapy, University of Cape Town and Groote Schuur Hospital.
}

\section{OPSOMMING}

Die belangrikste punte van 'n respiratoriese evaluering word aangedui. Elementêre mate wat deur die fisioterapeut geneem behoort te word, word beskryf. Eenvoudige longfunksietoetse, wat deur fisioterapeute, wat ervare is in die behandeling van respiratoriese pasiente, uitgevoer kan word, word in redelike detail verduidelik. Die betrokke toetse is: Piek Ekspiratoriese Vloeisnelheid, Geforseerde Vitale Kapasiteit, Geforseerde Ekspiratoriese Volume in 1 sekonde en die verhouding van Geforseerde Ekspiratoriese Volume in 1 sekonde tot Geforseerde Vitale Kapasiteit aangedui as 'n persentasie. Nog vier gevorderde toetse en hul onderliggende konsepte, wat verkieslik deur spesiale pulmonale toetslaboratoriums uitgevoer behoort te word, word kortliks beskryf.

Other special investigations and measurements may be classified as elementary, simple and advanced.

\section{ELEMENTARY SPECIAL INVESTIGATIONS AND MEASUREMENTS}

The only equipment required for the elementary measurements is a tape-measure and a watch with a sweep second hand.

\section{Chest Expansion}

The circumference of the chest at three levels is taken resting, after full expiration and then after full inspiration. The best of three readings is taken and recorded. The levels are: axilla (approximately 4th rib); xiphoid process; tenth costal cartilage (lowest point of complete rib cage). The difference between the full expiratory and full inspiratory values is the expansion.

\section{Exercise Tolerance}

Severe shortness of breath would have been noticed during the Observation section of the assessment. To measure exercise tolerance more objectively, an exercise load is imposed on the patient, the respiratory and pulse rates being noted before and for two minutes after completion of the exercise.

Respiratory rate. Taken for 1 minute before exerciso and at 2 minutes after exercise. It should have returned to the resting value by then.

Pulse ratio. Resting rate noted before exercise and then for 2 mins. after exercise. Divide the number of beats in the 2 mins. after exercise by the resting rate. Normal ratio is less than 2,5 .

Any appropriate exercise may be used, such as the Harvard step-test or some functional activity such as getting out of bed or taking a short walk.

In addition, if the patient is ambulant, the greatest distance he can comfortably cover and the time taken to do so should be noted and checked from time to time.

\section{SIMPLE LUNG FUNCTION TESTS}

The simple lung function tests which will be dealt with in some detail here are within the scope of any physiotherapist involved in treating chest conditions.

They are measurement and interpretation of:

- Peak Expiratory Flow Rate (Peak Flow or PEFR). - Vital Capacity (VC) and Forced Vital Capacity 
(FVC).

- Forced Expiratory Volume in $1 \mathrm{sec}$. $\left(\mathrm{FEV}_{1,0}\right.$ also written $\mathrm{FEV}_{1}$ ).

- Derived from the last two, the ratio of $\mathrm{FEV}_{1,0} / \mathrm{FVC}$ or $\mathrm{FEV}_{1} / \mathrm{FVC}$

These tests involve spirometry (measuring of breath) and therefore, a normal spirogram is presented as an introduction (fig. 1).

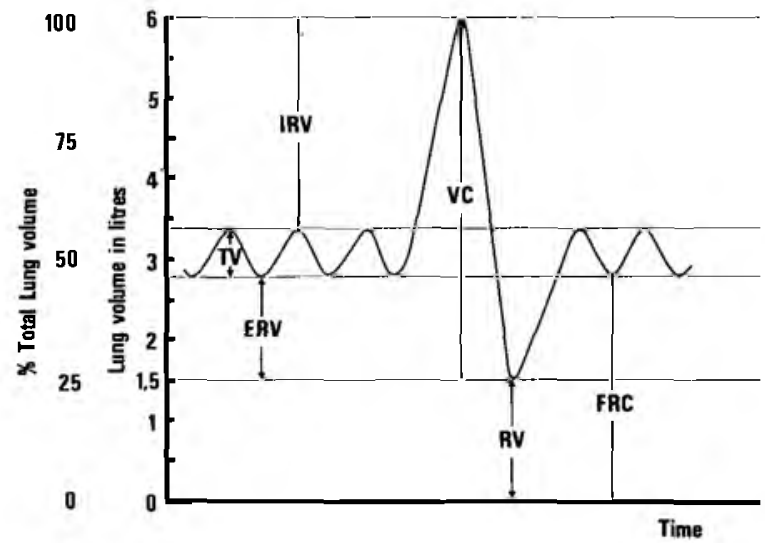

Fig. 1. A spirogram of a subject breathing normally, then taking a full deep breath, breathing out fully and then returning to normal breathing. TV - tidal volume, $\boldsymbol{E R V}$ - expiratory reserve volume, IRV - inspiratory reserve volume, VC vital capacity, RV - residual volume, FRC functional residual capacity. The tidal volume is between 0,5 and 0,6 litres.

A spirogram of a single full (forced) expiration from full inspiration to complete voluntary expiration is also shown (fig. 2). In this case, the volume of expired air is plotted against time in seconds as this is how the commonly used clinical spirometers present the result.

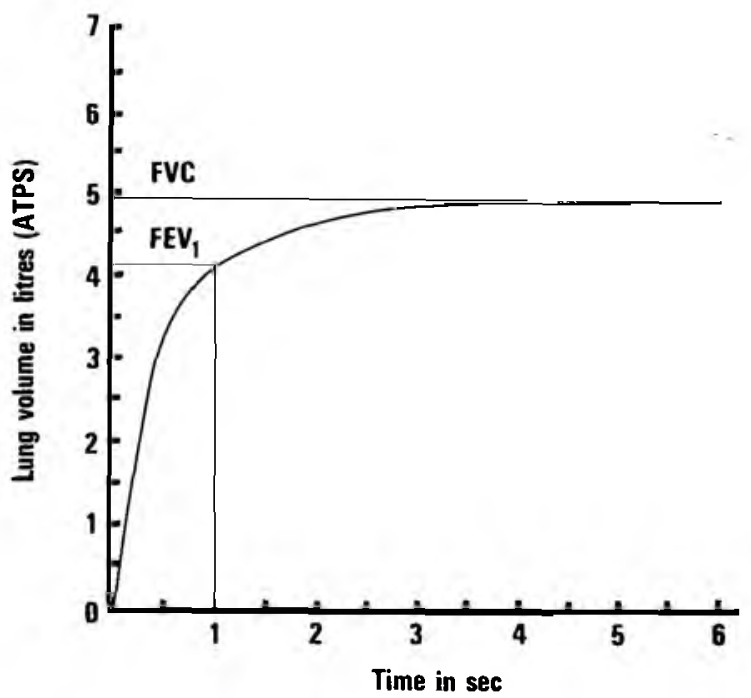

Fig. 2. Spirogram of a single, full, forced expiration showing FEV 1 and FVC.

\section{Peak Expiratory Flow Rate (PEFR)}

This is a flow rate (i.e. volume per unit time). It is the fastest instantaneous flow rate achieved during explosively forced expiration after full inspiration, irrespective of exactly when during the expiration it is achieved. However, if high speed turbulence occurs, indicated by stridor, a lower reading is obtained. It is analogous to an anemometer which measures wind speed during the night, the pointer remaining at the speed of the strongest gust of wind whenever it occurred.

\section{Measurement}

Peak expiratory flow rate may be read off a spirogram where it corresponds to the steepest part of the curve, i.e. when there is the greatest volume of air expired in the shortest time. As this point may be difficult to perceive on the graph by eye, the slope is usually read off as the time taken to expire a single litre of air near the start of the expiration and then converted to flow rate in litres $/ \mathrm{min}$. or litres $/ \mathrm{sec}$. In the case of the Vitalograph Single Breath Spirometer (Fig. 3) the slope of a line joining 0,2 litres to 1,2 litres of air expired is read, using a plastic protractor precalibrated to read flow rate directly.

More usually, a specific peak flow meter is used. Probably the best known type is the Wright's Peak Flow Meter (fig. 4). This instrument is $14 \mathrm{~cm}$ in diameter and $6 \mathrm{~cm}$ deep. It must be held vertically with the dial facing to the patient's right. In this instrument, the needle shows the peak flow rate maintained for a period of 0,01 sec. Although the "big" Wright's has been the standard peak flow meter for many years, it is a somewhat delicate instrument with fine moving parts. In the past few years, a Wright's Mini Peak Flow Meter (fig. 4) has been introduced. This is a plastic cylinder $13 \mathrm{~cm}$ long and $4,3 \mathrm{~cm}$ in diameter. It has been shown to have good reproducibility of results and a high correlation over the whole range with the "big" Wright's meter (M.R.C.). Vitalograph have also produced a similar simple instrument called the Vitalograph Pulmonary Monitor whose readings are correlated to peak expiratory flow rate and forced expiratory volume in 1 sec. The best of three readings is taken.

\section{Interpretation}

The PEFR obtained for a particular patient must be compared with the predicted value for a subject of the same sex, age and height, e.g. female, 30 years and $160 \mathrm{~cm}\left(5^{\prime} 3^{\prime \prime}\right)$, normal PEFR is 474 litres $/ \mathrm{min}$. Af reduced value is generally taken as an indication of airways narrowing. However, it is not regarded as very reliable, especially for patients suffering from acute bronchospasm, as the test requires considerable patient effort and co-operation and, in such acute cases, it often aggravates the bronchospasm. The patient soon learns to avoid this by "not trying so hard". In turn, this produces a lower than expected reading in a patient who is obviously clinically improved. The test does, however, have great use in monitoring the state of airways narrowing in chronic cases. PEFR recordings taken and recorded three times daily by the patient help in both the classification of the disease and in deciding on optimal management (Turner-Warwick, 1977). This technique is now in wide use among both general practitioners and respiratory physicians. Physiotherapists concerned with such patients should be familiar with the concept.

When making volume measurements, the volumes recorded by the spirometer are at ambient temperature and pressure, and saturated with water vapour (ATPS). If great accuracy is required, these should be converted 


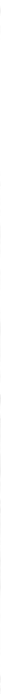

Fig. 3. A Vitalograph single-breath, werlge-bellows. dry Spirometer.

to body temperature and barometic pressure also saturated with water vapour (BTPS). The Vitaloglaph graphs have both volume scales valid tol most test conditions.

Vital Capacity (VC) and Forced Vital Capacity (FVC)

Both of these are the maximum volume of ail (measured in litres) which can be expelled alter maximum inspiration. The difference is that, for $V C$, the time taken for exhalation is not considercel, whereas, for FVC, the breath must be expelled as rapidly and completely as possible. As a test of pulmonary function. it is usually the FVC which is measured.

\section{Measurement}

FVC is measured by a sprrometer in the clinucal sei ting, usually the dry bellows type (Virologroph). A small instrument, the Wright's Respirometer is available which is suitable for measuring vital capacity and minute volume (total volume of air exhaled in onc minute, i.e. - I vol. $x$ respiratory ratel at expiratory flow rates becween 3,0 litres/min. and 300 litres/min. Below 3.0 litres/min. it does not register and above 300 litues/ min. the delicate mechanism may bc damaged, therefore, it is not suitable for use with iairly healthy adults who can produce PEFRs of up to 600 litres/ min. (Daykin et al. 1978).

The technique is 10 instruct the subject (preficrably standing) to breathe out, then to take as deep a breath as possible, put the mouthpiece into his mouth, to blow out as harcl as he can and to carry on until he has absolutely no breath left, being verbally encouraged all the time by the operator. The best of threc performances is taken.

\section{Interpretation}

Normal values of FVC vary directly with height. inversely with age and are lower in f'emales. The piedicted normal values for an indivisual should be determined from a nomogram before inlerpieting the results. Also, for patients with obstructive airvays or restriclive lung disease, the valuc of FVC should be compared with that of the forced expiratory volume in 1 sec. If possible, it should also be compared with
Fig. 4. Wright's Peak Flow Meter (left) and Wright's Mini Peak Flow Meter (right).

lolal lame capacio' but this is an advanced pulmonary function test. However. FVC is an important test Lor patuents who have euther a thoracic delormily such as kyphoscoliosis or ankylosing spondylitis or weakness of the respiratory muscles. Pain or mechanical interficience with breathing. e.g. fractured ribs, can also l'educe the FVC. A malkedly reduced FVC indicates a greater danger ol chest infection or post-operative chest complications and a recluced ability to cope with it. It can alcrt the team to a possible need to mechanically ventilate a patient at risk. In an adult, an FVC lalling, over time, towards 1 litre is regarded as life threatening. In the absence of a spirometer, a rough lute of thumb which may be helpful is to ask the patient 10 take as deep a breath as possible, then to count steadily out aloud unit they run ont of breath. An inability to reach above twenty suggesls a dangerously low ve

Forced Expiratory Volume in 1 sec. (FEV

This is the volume (measured in litres) which is expired during the first second of a forccel cxpiration. Somelumes the volume may be measureal over a dilterent period such as the first $0.5,2,0$ or $3.0 \mathrm{sec}$ but the common measurement is that over $1,0 \mathrm{sec}$.

\section{Mecasuremen}

The FEV, is most easily read of a single forced expiration spirogram such as that obtained with a Vitalograph and is taken from the best of the three FVC recordings.

\section{Imerpreration}

FEV, as with FVC, varies directly with height, inversely with age and is lower in females. The predicted normal value for the subject should be ascertianed.

Since the FEV, is a measurc of volume expired during a fixed unit of time, it is actually a measure of flow. to be precise the flow-resistance in the airways greater than $2 \mathrm{~mm}$ in ciameter. A reduced FEV, indicales increased resistance of the airways as lound in both obstructive alrways discise (chronic bionchitis. emphyscma, chronic asthma, etc.) ans in restrictive lung disease (pulmonary fibrosis of oedema). Probably 
its most important application, however, is in correlating it to the patient's FVC.

Ratio of Forced Expiratory Volume in 1 sec. to Forced Vital Capacity (FEV, /FVC)

This ratio, expressed as a percentage, should be derived from the same breath, i.e. the percentage of the total exhalation which the subject can breathe out in the first second.

\section{Measurement}

This is a calculation based on the $\mathrm{FEV}_{1}$ and FVC of a single exhalation usually measured on a single breath spirometer. It is expressed as a percentage. Some authorities may also use the FEV over a period other than the first second. This would always be denoted by the subscript to FEV.

\section{Interpretation}

The normal value of $\mathrm{FEV}_{1} / \mathrm{FVC}$ is $80 \%$ with a range from $75-85 \%$, A reduced value indicates airways narrowing of the obstructive type. The ratio is often normal for patients with restrictive disease as both readings are reduced in proportion to each other.

\section{ADVANCED LUNG FUNCTION TESTS AND CONCEPTS}

These are numerous and of a sophistication limited only by the resources and ingenuity of the laboratory concerned. Both their performance and interpretation are beyond the scope of most physiotherapists; however, a few remarks about some of the more common advanced tests and related concepts may be helpful.

\section{Blood Gas Analysis}

Often commonly referred to as "the Astrup", this is a measurement of the partial pressure of oxygen and carbon dioxide in the arterial blood. The normal values, in. SI units, are $\mathrm{PaO}_{2}=9,5-13,9$ kilopascals $(\mathrm{kPa} .1 \mathrm{kPa}=7,5 \mathrm{mmHg}), \mathrm{PaCO}_{2}=4,1-6,1 \mathrm{kPa}$. From these two, the acidity/alkalinity of the blood can be calculated. Normal arterial pH is 7,4 (range 7,38$7,46)$. In threatening respiratory failure, the $\mathrm{PaO}_{2}$ falls, $\mathrm{PaCO}_{2}$ rises and $\mathrm{pH}$ falls (becomes more acid).

\section{Flow/Volume Loop}

The subject performs a forced inspiration followed by a forced expiration into an instrument which records both the flow-rates achieved and the volumes of gas moved and automatically plots the flow-rate against the volume. As it is a closed system, a closed loop is obtained. This is a comparatively simple test and yet yields valuable information. which can be used to characterise and differentiate the various types of airways dysfunction (Rudnick et al., 1980).

\section{Ventilation/Perfusion Ratio}

For satisfactory lung function, not only must adequate volumes of air be ventilated through the lungs, but the air must be in contact, through the alveolar membrane, with adequate volumes of blood perfusing the lung. The ventilation/perfusion ratio varies in different regions of the lungs depending on posture. Overall it is approximately $1: 1$ at 5 litres $/ \mathrm{min}$. each. In the erect posture, it is greater than 1 in the apices and less than 1 in the bases. A serious deviation results in unsatisfactory gas transfer between the air and blood leading to hypoxia and hypercapnia (raised $\mathrm{PaCo}_{2}$ ).

\section{Compliance}

This term may be applied to the chest wall or the lungs or the combined system. It is defined as "the change in volume per unit change in pressure". Thus "stiff lungs" or an immobile chest wall (or both) only alter slightly in volume for a unit change of pressure and therefore have low compliance. A series of values is always taken, depending on the technique used, to produce a volume/pressure curve which is then interpreted. Measurements of lung compliance are particularly important in judging the pressures required for artificial ventilation in patients with stiff lungs such as following Paraquat poisoning.

Further information on advanced lung function tests is given by the appropriate texts mentioned in the Bibliography.

\section{CONCLUSION}

Scientific and medical knowledge in the fields $g^{f}$ respiratory physiology and pathology is expanding the time. In order to retain credibility as an important member of the treatment team, it behoves the concerned physiotherapist to be a master of chest assessment including the elementary measurements, to be competent at carrying out and knowing the significance of the simple lung function tests and to be familiar with the advanced tests.

\section{References}

Daykin, A. P., Nunn, G. F. and Wright, B. M. (1978). Tho measurement of vital capacity and minute volume with the Wright Respirometer. Brit. J. Dis. Chest, 72, $333-335$.

Morrison, S. C. (1980). Auscultation of the chest, S.A. J. of Physiother. 36, 66-69.

M.R.C. Pneumoconiosis Unit, Llandough, U.K. Quoted in "Notes for the Doctor. Mini-Wright's Peak Flow Meter" distributed for Clement Clarke International Ltd., by Allen \& Hanbury, Wadeville, Transvaal.

Rudnick, H. L., Loots, J. M., Theron, J. J., Ker, J. A., and Meyer B. J. (1980). The flow volume curve as a diagnostic tool. $S$. Afr. Med. J., 58, $273-276$.

Turner-Warwick, M. (1977). On observing patterns of airflow obstruction in chronic asthma. Brit. J. Dis. Chest, 71, $73-86$.

\section{Bibliography}

Capel, L. H. (1979). A use of lung function studies, Ed. Downie, P. A. in: Cash's Textbook of Chest, Heart and Vascular Disorders for Physiotherapists, Faber and Faber, London, pp. 358 - 373.

Cherniak, R. M. (1977). Pulmonary Function Testing, lst Ed., Saunders, Philadelphia.

Lucking, M. T. (1966). The use of ventilatory function tests in physiotherapy. Physiother. 52, $420-424$.

Parry, A. (1980). Physiotherapy Assessment, 1st Ed., Croom Helm, London.

Ruppel, G. (1979). Manual of Pulmonary Function Testing, 2nd Ed., Mosby, St. Louis.

Spriggs, E. A. (1978). The history of spirometry, Brit. J. Dis. Chest 72, $165-180$.

West, J .B. (1977). Pulmonary Pathophysiology, 1st Ed., Williams and Wilkins, Baltimore.

Ibid (1979). Respiratory Physiology, 2nd Ed., Williams and Wilkins, Baltimore. 